\title{
PERLINDUNGAN HAK WARGA EMAS DALAM PERUNDANGAN DI MALAYSIA
}

\section{(The Protection of Senior Citizens' Rights in Malaysian Legislation)}

\author{
Hasiah Mat Salleh \\ hasiah@kuipsas.edu.my
}

Jabatan Syariah,

Fakulti Pengajian Islam, Kolej Universiti Islam Pahang Sultan Ahmad Shah.

Mohd Norhusairi Mat Hussin*

husairi@um.edu.my

Raihanah Hj Abdullah

raihanah@um.edu.my

Jabatan Syariah dan Undang-undang,

Akademi Pengajian Islam, Universiti Malaya.

Pengarang koresponden (Corresponding author): *

Rujukan artikel ini (To cite this article): Hasiah Mat Salleh, Mohd Norhusairi Mat Hussin \& Raihanah Hj Abdullah. (2022). Perlindungan hak warga emas dalam perundangan di Malaysia. Kanun: Jurnal Undangundang Malaysia, 34(1), 1-22. http://doi.org. 10.37052/kanun.34(1)no1

\begin{tabular}{|lllll}
\hline $\begin{array}{l}\text { Peroleh: } \\
\text { Received: }\end{array} \quad$ 25/10/2021 & $\begin{array}{l}\text { Semakan: } \\
\text { Revised }\end{array}$ & 8/12/2021 & $\begin{array}{l}\text { Terima: } \\
\text { Accepted: 18/12/2021 }\end{array}$ & $\begin{array}{l}\text { Terbit dalam talian: 2/1/2022 } \\
\text { Published online }\end{array}$
\end{tabular}

\section{Abstrak}

Warga emas ialah golongan rentan yang perlu dilindungi dan dibela. Jasa dan sumbangan mereka amat besar terhadap agama dan negara. Namun begitu, dewasa ini faktor urbanisasi, kerjaya dan pendidikan telah menjadikan golongan ini mula dipinggir dan diabaikan oleh masyarakatnya. Kes penderaan juga sering dipaparkan di media massa mahupun media cetak seiring dengan peningkatan populasi warga emas Malaysia dan dunia. Kajian ini bertujuan untuk melihat perlindungan warga emas yang sedia ada dalam perundangan negara bagi meneliti sejauh mana hak warga emas dilindungi di Malaysia. Kajian dilakukan menggunakan pendekatan kualitatif melalui kajian kepustakaan dan dianalisis secara analisis kandungan. Hasil kajian menunjukkan perundangan sedia ada melindungi hak warga emas secara umum, namun

(C) Dewan Bahasa dan Pustaka. 2022. This work is licensed under the term of the Creative Commons Attribution (CC BY) (http://creative commons.org/licenses/by/4.0/) 
masih belum menyeluruh untuk memenuhi keperluan hak-hak warga emas. Oleh itu, artikel ini mencadangkan dipinda perundangan sedia ada dan digubal perundangan khusus warga emas dalam perundangan sivil dan undang-undang Islam dengan perluasan skop perlindungan terhadap warga emas berpandukan Teori Keadilan dan Teori Maqasid Shariah.

Kata kunci: Perlindungan warga emas, hak warga emas, pindaan perundangan, perundangan sivil, undang-undang Islam, Malaysia

\begin{abstract}
Senior citizens are a vulnerable group of people who need to be protected and defended due to their immense contributions to religion and the nation. However, urbanisation, career and education have rendered this group to be marginalised and neglected. Cases of abuse are also frequently displayed in mass and print media as a result of the increasing population of senior citizens in Malaysia and around the world. This study aims to look at the existing protection of senior citizens in national legislation in order to examine the extent to which their rights are protected. The research was conducted using qualitative approach through library research and content analysis. This study found that the existing legislation protects the rights of senior citizens in general but it is still not comprehensive in fulfilling their interests. Therefore, this article proposes that the existing legislation be amended and legislation specifically for senior citizens be enacted in civil law and Islamic law with the expansion of the scope of protection for them based on the Theory of Justice and the Theory of Maqasid Shariah.
\end{abstract}

Keywords: Protection of senior citizens, rights of senior citizens, amendment of legislation, civil law, Islamic law, Malaysia

\title{
PENDAHULUAN
}

Isu peningkatan populasi warga emas dunia dan peningkatan kes penderaan serta pengabaian menjadi perbahasan utama di seluruh dunia. ${ }^{1}$ Pertubuhan Bangsa-Bangsa Bersatu melalui Resolusi Perhimpunannya (Resolusi

1 Khadija Alavi dan Mohd Suhaimi Mohamad Sarin Johari, 'Perbandingan Tahap Kualiti Hidup Bagi Warga Emas Yang Mendapatkan Perkhidmatan Di Pusat Aktiviti Warga Emas (PAWE) Di Kawasan Bandar Dan Luar Bandar (Jurnal Psikologi Malaysia, 32.3 (2018), 82-90; Zaitie Satibi, 'Kian Ramai Warga Tua Didera Harian Metro', Harian Metro, 2017 <https://www.hmetro.com.my/sihat/2017/07/243481/ kian-ramai-warga-tua-didera $>$ [diakses 17 March 2018]. 
46/91) pada 16 Disember 1991 memandang serius perkara ini dan menyediakan suatu resolusi tindakan untuk dunia menghadapi keadaan ini agar hak warga emas terbela dan dilindungi. ${ }^{2}$ Terdapat 18 prinsip yang digariskan di bawah lima tema utama perlindungan warga emas, iaitu kebebasan, penyertaan, penjagaan, kepuasan diri dan maruah. Prinsip dan tema ini menjadi panduan kebanyakan negara dunia untuk mendepani isu warga emas termasuklah Malaysia.

Malaysia memandang serius perkara ini dengan mengambil langkah untuk membendung masalah ini daripada berleluasa dengan mewujudkan Dasar Warga Emas Kebangsaan (DWTK) ${ }^{3}$ pada tahun 1995. Dasar ini dibentuk berpandukan sebelas resolusi, pelan tindakan, strategi dan garis panduan daripada Pertubuhan Bangsa-bangsa Bersatu termasuklah Principle for Older People 1991 (Resolusi 46/91) pada 16 Disember 1991. Setahun selepas diwujudkan dasar ini, satu pelan tindakan dan polisi warga emas digubal dengan enam strategi utama, iaitu mewujudkan peluang pembelajaran sepanjang hayat; kenaikan pangkat dan penyokongan; jaminan keselamatan dan cagaran; tadbir urus dan tanggungjawab bersama; perpaduan antara generasi dan penyelidikan dan pembangunan. ${ }^{4}$ Pelan ini kemudian dikaji semula pada tahun 2008 dengan mewujudkan Dasar Kebangsaan Baru Warga Emas yang disahkan pada tahun $2011^{5}$ yang bertujuan untuk menggalakkan penyediaan kemudahan untuk kesejahteraan kewangan dalam bentuk insurans, demi menjamin

2 Older People's Commissioner for Wales, "United Nation Principle. Laman Sesawang diakses 9 Oktober 2021, https://www.olderpeoplewales.com/en/about/un-principles. aspx

3 TengkuAizanHamid, National Policies on Ageing- Malaysia, Ageing and LongTerm Care, $2018<\mathrm{https} / / /$ doi.org/10.1355/9789812307163-007>; JKM, 'Dasar Warga Emas Negara', Jabatan Kebajikan Masyarakat Malaysia, $2015<$ https://doi. org/10.1017/CBO9781107415324.004>.

4 Kementerian Pembangunan Wanita Keluarga dan Masyarakat, Pelan Tindakan Warga Emas Negara (PTWEN), Kementerian Pembangunan Wanita Keluarga Dan Masyarakat, $2015<\mathrm{http}: / /$ www.kpwkm.gov.my/dasar1?p_p_id=XY_CMS MULTI_WAR_xycmsp?_XY_CMS_MULTI_WAR_xycmsportlet_INSTĀNCE FC8h_andOperator=true $>$.

5 JKM; Kementerian Pembangunan Wanita Keluarga dan Masyarakat; 'Portal Rasmi Jabatan Kebajikan Masyarakat' <http://www.jkm.gov.my/jkm/index.php?r=portal/le ft\&id=VzNXN1VHM0hxZ3VqWWhZS0RhMDZidz09> [diakses 24 March 2020]; Che Kiong Lim, 'The Changing Needs Of Older Malaysians: A Selangor Case Study', Discipline of Geography, Environment and Population Faculty of Humanities and Social Sciences The University of Adelaide (University of Adelaide, 2012). 
penjagaan dan perlindungan warga emas di negara ini ke arah memastikan kebajikan serta kesejahteraan hidup mereka terpelihara. ${ }^{6}$

Selain itu, dalam aspek perlindungan kesihatan warga emas, Kementerian Kesihatan membangunkan Dasar Kesihatan Warga Emas Negara (DKWEN) pada tahun $2008^{7}$ bersama enam prinsip panduan, iaitu memelihara autonomi, mengiktiraf keperluan orang emas, membantu penjaga, menggalakkan penuaan yang sihat, memberikan penjagaan yang berterusan dan mengekalkan hak warga emas untuk mencapai kualiti hidup. Melalui dasar ini, kerajaan menzahirkan komitmen untuk memastikan warga emas dapat mencapai kesihatan yang optimum melalui perkhidmatan kesihatan dan kesihatan yang komprehensif. Dasar ini diikuti dengan pelancaran Dasar Warga Emas Negara oleh Kementerian Pembangunan Wanita, Keluarga dan Masyarakat (KPWKM) yang bertujuan untuk memberikan jaminan keselamatan dan perlindungan dalam semua aspek, tanpa memilih latar belakang agama, bangsa dan keturunan. ${ }^{8}$

Namun begitu, dasar dan polisi ini tidak akan dapat terlaksana dengan berkesan tanpa sokongan perundangan yang menguatkuasakan susun atur tingkah laku manusia untuk memelihara hak warga emas yang digariskan. Beberapa perundangan sedia ada amat penting untuk menjadi penyokong dan sandaran kepada dasar dan prinsip ini untuk pelaksanaannya. Namun begitu, sejauh mana perundangan yang ada merealisasikan hasrat dasar dan polisi yang diwujudkan? Hal tersebut memerlukan penelitian yang mendalam. Oleh itu, kajian ini meneliti perundangan sedia ada untuk melihat aspek yang dilindungi oleh perundangan tersebut. Metodologi kajian ini menggunakan pendekatan kualitatif dengan penelitian kepada statut sedia ada, dasar, polisi, kajian terdahulu, buku dan laporan kes. Dokumen tersebut dianalisis secara analisis kandungan bagi memperoleh skop perlindungan yang telah dilaksanakan dan belum dilaksanakan bersama-sama dengan cadangan yang bersesuaian.

6 Lim; Nor Raudah Siren, 'Psikologi Dan Penerimaan Warga Emas Di Kompleks Warga Emas Al-Jenderami', Jurnal Usuluddin, 41.Januari-Jun (2015), 73-93; JKM.

7 'Portal Rasmi Jabatan Kebajikan Masyarakat'; KPWKM, 'Dasar Kesihatan Warga Emas Negara', Kementerian Pembangunan Wanita, Keluarga Dan Masyarakat, 2016, 1-21 <https://doi.org/10.1017/CBO9781107415324.004>.

Lihat JKM. Rujukan penuh. 


\section{UNITED NATION PRINCIPLES FOR OLDER PERSONS (UNPOP) 1991}

United Nation Principles For Older Persons (UNPOP) 1991 telah diwujudkan oleh Pertubuhan Bangsa-Bangsa Bersatu pada 16 Disember 1991 dikenali sebagai Resolusi 46/91. ${ }^{9}$ Resolusi yang mengandungi lima tema utama bersama-sama dengan 18 prinsip yang dihasilkan atas kesedaran peningkatan populasi warga emas dunia dan keperluan menghargai kepelbagaian keupayaan, sokongan, peluang penyertaan dan tahap kesihatan yang baik. Lima tema tersebut ialah kebebasan, penyertaan, penjagaan, kepuasan diri dan maruah. Prinsip kebebasan dalam UNPOP bagi tema pertama meliputi kebebasan untuk mendapatkan keperluan asas, penjagaan kesihatan, pendapatan yang wajar, melalui peluang pekerjaan, dan menjana pendapatan, memperoleh pendidikan dan latihan, peluang untuk hidup dalam persekitaran yang selamat yang sesuai dengan keinginan dan kediaman selama yang diperlukannya. ${ }^{10}$ Namun begitu, menurut Olga Overbury (2005), pelaksanaannya dalam dunia pekerjaan masih belum berjaya tanpa melibatkan diskriminasi. ${ }^{11}$

Tema kedua ialah penyertaan warga emas. Warga Emas berhak diberikan peluang menyertai dan berintegrasi dalam masyarakat dan negara untuk menyumbangkan ilmu, kemahiran dan pengalaman mereka. Selain itu, warga emas juga wajar diberikan peluang untuk meneruskan khidmat kepada masyarakat dan perkhidmatan sama ada secara sukarela atau lantikan jawatan yang sesuai berdasarkan minat dan kemampuan mereka serta peluang mewujudkan persatuan dan penyertaan dalam persatuan. Tema ketiga ialah penjagaan terhadap warga emas yang meliputi hak penjagaan dan perlindungan bersama-sama dengan keluarga dan masyarakat sesuai dengan sistem nilai budaya yang ada. Akses kepada rawatan kesihatan juga perlu bagi mengekalkan tahap kesejahteraan fizikal, mental dan emosi yang optimum, begitu juga dengan akses untuk perkhidmatan sosial, undangundang dan institusi rawatan bagi meningkatkan autonomi, perlindungan dan penjagaan mereka. Warga emas juga berhak menikmati hak asasi manusia dan kebebasan asasi dalam kehidupan mereka yang bersesuaian dengan hak asasi manusia yang lain.

9 OHCHR | United Nations Principles for Older Persons' https://www.ohchr.org/en/ professionalinterest/pages/olderpersons.aspx [diakses 22 Ogos 2021].

10 Olga Overbury, Walter Wittich, and Pat Spadafora, 'United Nations' Principles for Older Persons Viewed Though the Eyes of Visually Impaired Seniors', International Congress Series, 1282 (2005), 428-32.

Overbury, Wittich, and Spadafora. Muka surat? 


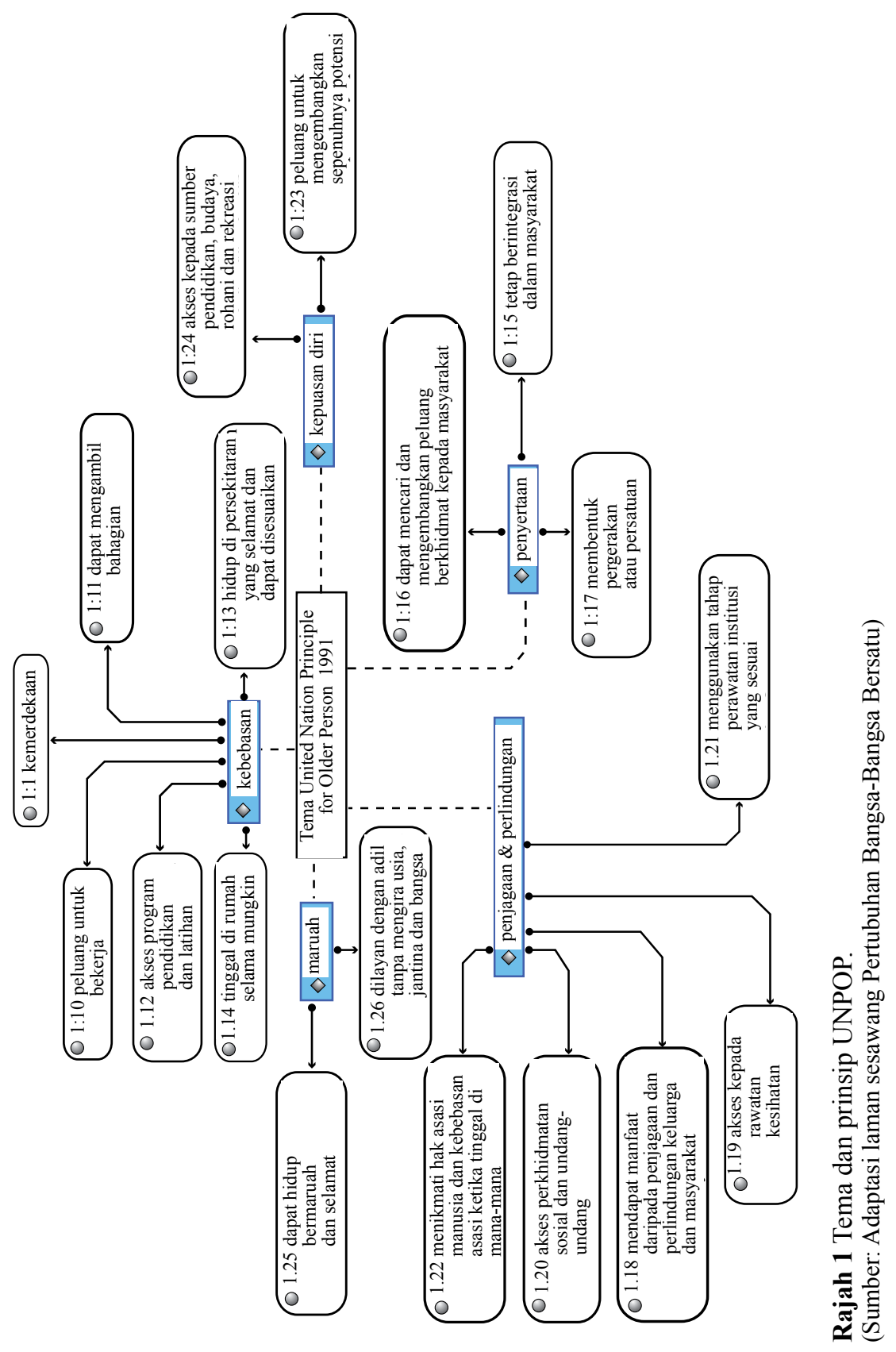


Tema keempat ialah kepuasan diri. Warga emas berpeluang untuk mengembangkan potensi yang ada dalam diri mereka dan mempunyai akses kepada sumber pendidikan, budaya, rohani dan rekreasi masyarakat mereka. Tema kelima ialah maruah warga emas. Warga emas berhak hidup secara bermaruah dan selamat dengan kebebasan daripada eksploitasi dan penderaan, dan diberikan layanan yang adil, dihargai atas sumbangan yang telah mereka berikan kepada mayarakat dan negaranya.

Secara umumnya lima tema ini menjadi panduan kepada pembentukan dasar dan polisi warga emas di Malaysia seperti yang terkandung dalam rujukan kepada Dasar Warga Emas Negara (DWEN) di perkara 3(ii). ${ }^{12}$ DWEN disokong pelaksanaannya di bawah Pelan Tindakan Dasar Warga Tua Negara 1998 bersama-sama dengan 16 nilai murni dan enam strategi termasuk aspek keselamatan dan perlindungan yang perlu dimasukkan dalam peruntukan undang-undang sedia ada. Jika diteliti, walaupun UNPOP menjadi rujukan dasar dan polisi warga emas negara, aspek pelaksanaan dalam undang-undang sedia ada masih tidak dimasukkan secara menyeluruh. Penyataannya hanya diletakkan secara umum dan memerlukan huraian yang menyukarkan perlindungan hak warga emas dilaksanakan. Keadaan ini menyebabkan hukuman pelanggaran hak warga emas sukar dilaksanakan. Tema dan prinsip UNPOP adalah seperti Rajah 1.

\section{KERANGKA PERLEMBAGAAN PERLINDUNGAN WARGA EMAS}

Perlembagaan Persekutuan (PP) merupakan undang-undang tertinggi di negara ini. PP merupakan undang-undang utama yang melindungi hak warga emas di Malaysia. Kewujudan PP bersesuaian dengan Teori Keadilan oleh John Rawls dan beberapa elemen kebebasan serta hak asasi warga emas melalui UNPOP telah diadaptasikan. ${ }^{13}$ Antaranya termasuklah perkara 5 sehingga perkara 13 yang menggariskan aspek kebebasan kepada semua manusia termasuk warga emas dalam aspek kebebasan diri, larangan menjadi hamba atau pengabdian, perlindungan undang-undang jenayah yang tidak adil (ke belakang dan perbicaraan berulang), kesamarataan undang-undang dan perlindungan undang-undang, kebebasan bergerak dan

12 https://www.kpwkm.gov.my/kpwkm/uploads/files/Dokumen/Dasar/Dasar\%20 Warga\%20Emas_2011.pdf

13 Pan Mohamad Faiz, Teori Keadilan Jhon Rawls, Jurnal Konstitusi. Vol 6. No.1(2009) dan lihat https:/www.kpwkm.gov.my/kpwkm/uploads/files/Dokumen/Dasar/ Dasar\%20Warga\%20Emas_2011.pdf 
larangan buang negeri, kebebasan bercakap, berhimpun dan berpesatuan yang tidak menggugat ketenteraman awam, kebebasan beragama dan mengamalkan agama serta hak terhadap harta. ${ }^{14}$ Menurut Tengku Aizan dan Nurizan Yahya (Country Report Malaysia 2012) menyatakan bahawa hak perlindungan dan kesamaratan ini adalah penting untuk memberikan sokongan persekitaran terhadap warga emas. Kedua-dua hak ini amat membantu aspek kecekapan urus tadbir hal ehwal warga emas dan penguatkuasaan undang-undang yang berkaitan dengan warga emas. ${ }^{15}$

Walaupun peruntukan PP yang ada bersifat umum bagi semua warga namun peruntukan ini suatu pengiktirafan kepada hak asasi warga emas yang terdapat dalam perundangan di Malaysia. Sungguhpun tiada dinyatakan secara khusus perlindungan hak tersebut kepada warga emas, namun peruntukan ini memberikan ruang yang luas bagi penyediaan undang-undang khusus berkaitan dengan warga emas pada masa akan datang. Dari aspek perundangan Islam pula, didapati elemen perlindungan yang terdapat dalam perkara 5 sehingga perkara 11, PP adalah wajar diperluas pada masa akan datang yang meliputi aspek harta dan keturunan seperti yang dinyatakan dalam objektif perundangan Islam, iaitu bagi memelihara agama, nyawa, akal, keturunan dan harta. Aspek kebebasan diri, perlindungan undang-undang, kesamarataan undang-undang kebebasan bergerak, kebebasan bercakap, berhimpun, berpersatuan, kebebasan beragama dan mengamalkan agama yang ditekankan oleh peruntukan perlembagaan persekutuan hanyalah terhadap hak perlindungan agama, nyawa dan akal sahaja. Hak perlindungan terhadap harta pula terlalu umum dan tidak dinyatakan perlindungan dalam aspek keturunan dan maruah. Seksyen 13 perlindungan terhadap harta menyatakan:

“(1) Tiada seorang pun boleh dilucutkan hartanya kecuali mengikut undang-undang.

(2) Tiada undang-undang boleh memperuntukkan pengambilan atau penggunaan harta dengan paksa tanpa pampasan yang memadai."

Peruntukan di atas menunjukkan masih terdapat kelompongan perlindungan harta warga emas dari aspek eksploitasi harta, kuasa autonomi, pengabaian bantuan kewangan warga emas, hak perwarisan dan lain-lain

14 Perlembagaan Persekutuan, 'Perlembagaan Persekutuan Malaysia', 1963.

15 Tengku Aizan Hamid and Nurizan Yahaya, 'National Policy for the Elderly in Malaysia: Achievements and Challenges', in Ageing in Southeast and East Asia: Family, Social Protection, Policy Challenges, 2008 https://doi.org/10.1355/9789812307941-009>. 
yang tidak dinyatakan dengan jelas. Dari aspek hak perlindungan keturunan dan maruah pula tiada dinyatakan dalam PP seperti hak berkeluarga, memilih pasangan, perlindungan keturunan dan maruah diri warga emas

Aspek-aspek yang dinyatakan dalam PP hanya memenuhi Teori Keadilan, namun masih belum menyeluruh memenuhi keperluan perundangan Islam seperti dalam Teori Maqasid Shariah. Oleh itu, perlindungan terhadap warga emas yang diperuntukkan dalam PP adalah belum menyeluruh seperti yang diperlukan oleh warga emas menerusi objektif perundangan Islam.

\section{UNDANG-UNDANG BAGI PERLINDUNGAN HAK WARGA EMAS}

Pada ketika penulisan ini lakukan, terdapat empat undang-undnag sivil sedia ada yang mengandungi aspek perlindungan warga emas di Malaysia, iaitu Kanun Keseksaan (Akta 574), Akta Keganasan Rumahtangga 1994 (Akta 521), Akta Orang-Orang Papa 1977 (Akta 183) dan Akta Pusat Jagaan 1993 (Akta 506). Dua lagi perundangan Islam yang melindungi warga emas, iaitu Undang-Undang Keluarga Islam Negeri dan UndangUndang Pentadbiran Agama Islam Negeri.

\section{Kanun Keseksaan (Akta 574)}

Kanun Keseksaan (KK) merupakan undang-undang yang penting di Malaysia bagi melindungi manusia daripada jenayah terhadap diri, keluarga dan agama. Kesalahan jenayah yang dinyatakan oleh KK meliputi jenayah berkenaan dengan agama ${ }^{16}$, nyawa dan tubuh badan ${ }^{17}$, mencederakan ${ }^{18}$, mengurung ${ }^{19}$, serangan dan kekerasan jenayah $^{20}$, penculikan dan penghambaan ${ }^{21}$, tebusan ${ }^{22}$, $\operatorname{rogol}^{23}$, sumbang mahram ${ }^{24}$, kesalahan

16 Sek 295-298A, Kanun Keseksaan

17 Sek 299- 318, Kanun Keseksaan

18 Sek 319-338, Kanun Keseksaan

19 Sek 339-348 Kanun Keseksaan

20 Sek 349-358 Kanun Keseksaan

21 Sek 359-374 Kanun Keseksaan

22 Sek 374A Kanun Keseksaan

23 Sek 375-376 Kanun Keseksaan

24 Sek 376A-376B Kanun Keseksaan 
persetubuhan luar tabii ${ }^{25}$, jenayah terhadap harta yang meliputi mencuri ${ }^{26}$, memeras $^{27}$, merompak ${ }^{28}$, salahguna harta ${ }^{29}$, pecah amanah $^{30}$, menerima harta hasil mencuri ${ }^{31}$, menipu ${ }^{32}$, perbuatan khianat ${ }^{33}$, menceroboh $^{34}$, jenayah berkaitan perkahwinan ${ }^{35}$, fitnah ${ }^{36}$ dan perbuatan yang boleh menimbulkan ketakutan. ${ }^{37}$ Semua kesalahan jenayah yang dinyatakan ini melindungi setiap individu daripada sebarang perbuatan jenayah termasuk warga emas.

Antara kesalahan yang sering melibatkan warga emas adalah seperti perbuatan mencederakan warga emas. Perbuatan tersebut boleh dihukum di bawah seksyen 323 dan 325 Kanun Keseksaan. ${ }^{38}$ Namun begitu, kecederaan yang dimaksudkan bergantung pada tahap kecederaan yang berlaku kepada warga emas. Bagi kesalahan di bawah seksyen 323 pesalah yang melakukan kesalahan terhadap warga emas dengan seksaan secara sengaja memberikan kecederaan boleh dikenakan hukuman penjara satu tahun atau denda RM2000.00 atau kedua-duanya sekali. Bagi kecederaan yang dilakukan terhadap warga emas secara sengaja yang menyebabkan kecederaan parah di bawah seksyen 325 yang boleh dihukum penjara selama tujuh tahun dan denda. Perlindungan ini adalah untuk kecederaan dan penyeksaan fizikal yang dilakukan terhadap warga emas yang tidak berkeluarga atau selain daripada anggota keluarga. Sebagai contoh dalam kes Tan Peng Huat lwn Tan Hee Soon ${ }^{39}$ yang melibatkan kecederaan yang dilakukan oleh defenden terhadap plaintif seorang warga emas yang berusia 68 tahun.

\footnotetext{
25 Sek 377-377E Kanun Keseksaan

26 Sek 378-382A Kanun Keseksaan

27 Sek 383-389 Kanun Keseksaan

28 Sek 390-402 Kanun Keseksaan

29 Sek 402A-404 Kanun Keseksaan

30 Sek 405-409B Kanun Keseksaan

31 Sek 410-414 Kanun Keseksaan

32 Sek 415-424 Kanun Keseksaan

33 Sek 425-440 Kanun Keseksaan

34 Sek 441-462 Kanun Keseksaan

35 Sek 493-498 Kanun Keseksaan

36 Sek 499-502 Kanun Keseksaan

37 Sek 503-510 Kanun Keseksaan

38 Baruddin Ahmad Ahmad, Muhammad Hazim, Sykran, 'Undang-Undang Penjagaan Dan Kebajikan Warga Emas Di Malaysia: Satu Analisis Awal', in Prosiding Industri Warga Emas Kebangsaan, Menuju Pengurusan Patuh Syariah (Universiti Sains Islam Malaysia, 2019). Sila semak nama pengarang yang tidak lengkap dalam artikel ini.
} 
Kes ini memberikan perlindungan kepada plaintif untuk memperoleh pampasan akibat kecederaan yang dialami ekoran serangan dan pukulan oleh fefenden dengan jumlah kos sebanyak RM45,000.00. Demikian juga dalam kes Mohamad Syahruwan bin Abdullah lwn Pendakwa Raya ${ }^{40}$ yang melibatkan kecederaan terhadap warga emas disebabkan oleh perbuatan samun oleh perayu. Dalam kes ini mahkamah mengekalkan hukuman sembilan tahun penjara dan empat kali sebatan ekoran kecederaan yang dialami oleh mangsa.

Bagi penderaan yang dilakukan oleh anggota keluarga terhadap warga emas hendaklah dibaca bersama dengan Akta Keganasan Rumahtangga 1994, iaitu bagi kesalahan domestik ${ }^{41}$ dan institusi. ${ }^{42}$ Kesalahan domestik melibatkan penderaan yang dilakukan oleh anak, pasangan atau ahli keluarga terhadap ibu bapa warga emas. Hal ini dijelaskan oleh Krug et al. (2002) untuk menghuraikan berkaitan dengan "penderaan warga emas" adalah apabila seseorang yang berada dalam kategori umur "tua" didera sama ada secara fizikal, seksual, emosi, kewangan atau pengabaian. Penderaan warga emas ialah:

Elder abuse is a single or repeated act or lack of appropriate action, occurring within any relationship where there is an expectation of trust which causes harm or distress to an older person. ${ }^{43}$

Antara perkara yang termasuk dalam kategori penderaan ialah pengabaian. Pengabaian berlaku apabila kegagalan menyediakan makanan, pakaian, perlindungan, rumah dan lain terhadap warga emas. ${ }^{44}$ Namun begitu, aspek ini tidak terdapat perlindungannya dalam Kanun Keseksaan dan menyukarkan perkara ini untuk dibendung.

Selain itu, penderaan fizikal terhadap warga emas yang dilindungi di bawah Kanun Keseksaan terdapat juga peruntukan yang melindungi warga emas dari aspek penderaan emosi seperti ugutan jenayah. Seksyen 506 Kanun Keseksaan ada memberikan perlindungan dalam aspek ini dengan mana-mana pihak yang melakukan ugutan jenayah yang boleh mendatangkan rasa takut dalam diri warga emas dengan niat menakut-

40 (2019) MLJU 647

41 Sek 3. Akta Keganasan Rumahtangga 1994.

42 Robert M Gordon and Deborah Brill, 'The Abuse and Neglect of the Elderly', International Journal of Law and Psychiatry, 24 (2001), 203-18.

43 Seng Cheong Loke and others, 'Assessment of Factors Influencing Morale in the Elderly', PLoS ONE, 6.1 (2011), 1-8 < https://doi.org/10.1371/journal. pone.0016490>.

44 New Sunday Times, 29 Mac 2015. 
nakutkan boleh dikenakan hukuman penjara dua tahun atau denda atau kedua-duanya sekali. Contohnya kes, seorang pemuda yang mengugut ibunya dengan ugutan jenayah dengan niat menakut-nakutkan ibunya sehingga melahirkan rasa ketakutan dalam diri ibunya ${ }^{45}$, dan kes Andika bin Anuar lwn Pendakwa Raya ${ }^{46}$ Dalam kedua-dua kes ini melibatkan penderaan emosi terhadap warga emas untuk tujuan mendapatkan apaapa yang dihajati oleh pendera. Hasil pertimbangan mahkamah rayuan terhadap kes Andika, mahkamah rayuan menolak rayuan perayu ekoran tindakan menakut-nakutkan mangsa yang terdiri daripada warga emas adalah sesuatu yang tidak boleh dianggap ringan, dan hukuman dikekalkan dengan penjara 10 tahun penjara dan sepuluh kali sebatan.

Sungguhpun kesalahan jenayah terhadap warga emas boleh dijatuhi hukuman berdasarkan Kanun Keseksaan ini namun tidak terdapat satu terma mahupun istilah khas yang dimasukkan dalam kanun ini yang membawa maksud warga emas seperti yang disediakan untuk kanakkanak dan wanita. Peruntukan yang ada hanyalah bersifat umum tanpa mengkhususkan terhadap perlindungan warga emas. Oleh itu, satu model perlindungan khusus bagi warga emas adalah wajar dilaksanakan seperti yang dicadangkan dalam kajian ini.

\section{Akta Keganasan Rumahtangga 1994 (Akta 521)}

Akta Keganasan Rumahtangga 1994 merupakan akta yang lebih rapat dan banyak digunakan bagi memenuhi aspek perlindungan warga emas dari segi penderaan fizikal dalam institusi keluarga. Walaupun tiada definisi jelas menyentuh berkaitan dengan istilah warga emas, namun akta ini menjadi rujukan dan sandaran utama dalam kes penderaan warga emas yang berlaku dalam keluarga yang dikenali sebagai domestic violent. ${ }^{47}$ Keganasan dalam keluarga yang berlaku terhadap warga emas perlu dibaca bersama-sama dengan Kanun Keseksaan bagi membolehkan suatu tindakan undangundang diambil terhadap yang melakukan jenayah tersebut.

Walaupun terdapat peruntukan dalam akta ini untuk melindungi warga emas daripada keganasan dalam rumah tangga, namun istilah warga emas

45 Zatul Iffah Zolkiply, 'Tak Mengaku Salah Mengugut Ibu Sendiri', Berita Harian Online, $2019<$ https://www.bharian.com.my/berita/kes/2019/03/538422/takmengaku-salah-mengugut-ibu-sendiri> [diakses 7 September 2021].

46 (2012) MLJU 1062

47 Jal Zabdi Mohd Yusoff, 'Jenayah Dalam Keluarga: Penderaan Dan Pengabaian Warga Tua Di Malaysia', International Conference on Corporate Law (ICCL), 2009. 
atau orang tua tidak dinyatakan secara jelas di dalamnya. Menurut Jal Zabdi (2015) dan Muhammad Hazim et al. (2015) untuk menghuraikan akta ini, mereka menyatakan bahawa tiada definisi yang jelas bahawa warga emas dilindungi di bawah undang-undang ini secara menyeluruh kecuali bagi warga emas yang berkeluarga sahaja. ${ }^{48}$ Istilah warga emas juga adalah tidak jelas digunakan dalam akta ini bahkan hanya menggunakan istilah "ibubapa ${ }^{49}$ " dan "orang dewasa yang tiada upaya." ${ }^{50}$ Istilah ini tidak cukup bagi memenuhi perlindungan terhadap warga emas secara menyeluruh bahkan boleh meragukan bagi warga emas yang masih berkeupayaan dan sihat atau warga emas yang tidak mempunyai anak.

Dalam aspek bentuk keganasan rumah tangga yang dilindungi terhadap warga emas berkeluarga dalam akta ini meliputi kesalahan ketakutan terhadap kecederaan fizikal ${ }^{51}$, mencederakan fizikal ${ }^{52}$, paksaan atau ancaman seksual ${ }^{53}$, mengurung tanpa rela $^{54}$, pengkhianatan atau kemusnahan harta yang membawa rasa sedih atau gusar ${ }^{55}$ dan perintah perlindungan (injuksi) ${ }^{56}$ untuk mangsa.

Perintah injuksi bagi mangsa dera atau keganasan rumah tangga adalah antara perkara yang dapat membantu warga emas berkeluarga daripada terus disakiti sama ada secara fizikal mahupun emosi. Perintah Perlindungan Sementara atau dikenali sebagai Interim Protection Order (IPO) ini selain berfungsi untuk mencegah pendera daripada terus mencederakan mangsa, juga membolehkan warga emas memperoleh pampasan ${ }^{57}$ dan kaunseling. ${ }^{58}$

48 Asiah Bidin and Jal Zabdi Mohd Yusoff, 'Abuse of the Malaysian Elderly: An Analysis on the Adequacy and Suitability of the Domestic Violence Act 1994 (Act 521) to Protect the Elderly Victim', Journal of Management Research, 7.2 (2015), $71<$ https://doi.org/10.5296/jmr.v7i2.6928>; Ahmad, Muhammad Hazim, Sykran. the abuse of the elderly is recognized as a form of domestic violence. The legislation dealing with matters pertaining to domestic violence is Domestic Violence Act 1994 (Act 521 Semak sitasi penuh bagi artikel Muhammad Hazim

49 Sek 2(a)(ii) Akta Keganasan Rumah Tangga 1994.

50 Lihat tafsiran "keganasan rumah tangga" Sek 2 (e)(iv) Akta Keganasan Rumah Tangga 1994.

51 'Akta Keganasan Rumahtangga (Akta 521)', 1994. Tafsiran keganasan rumah tangga Sek. 2(a).

52 Sek 2 (b)

53 Sek 2 (c)

54 Sek 2 (d)

55 Sek 2 (e)

56 Sek 4

57 Sek 10

58 Sek 11 
Pengkaji mendapati sungguhpun akta ini dapat memberikan perlindungan kepada warga emas, namun perlindungannya terhad kepada warga emas yang berkeluarga. Akta ini juga mengandungi perlindungan yang kurang menyeluruh ekoran penggubalan akta ini bertujuan untuk melindungi hak isteri bukannya menfokuskan hak warga emas. Menurut Asiah Bidin dan Jal Zabdi (2015) kewujudan Akta 521 ini timbul ekoran isu penderaan dan pembelaan kepada isteri yang menyebabkan rangka rang undang-undang ini lebih memenuhi keperluan perlindungan kepada isteri. ${ }^{59}$ Oleh itu, pengkaji mendapati akta ini kurang sesuai untuk dilaksanakan secara khusus kepada warga emas dan memerlukan pengkajian lebih menyeluruh untuk membangunkan model perlindungan warga emas secara khusus bagi memenuhi hak warga emas.

\section{Akta Orang-Orang Papa 1977 (Akta 183)}

Akta Orang-Orang Papa telah diwujudkan pada tahun 1977 bertujuan untuk memulihkan dan menjaga orang-orang papa. ${ }^{60}$ Akta ini menggantikan Akta Kutu Rayau 1965 yang telah dimansuhkan ${ }^{61}$ bagi menangani isu pengemis dan orang-orang yang tiada tempat tinggal daripada pelbagai golongan manusia termasuk warga emas. Warga emas yang terdiri daripada orang-orang papa akan dikumpulkan bagi mendapatkan penjagaan, perlindungan serta pemulihan. ${ }^{62}$ Penjagaan terhadap warga emas papa biasanya ditempatkan di Rumah Seri Kenangan untuk menjalani proses pemulihan dan penjagaan. Usaha ini dilihat sebagai suatu langkah positif bagi menangani masalah warga emas gelandangan, tiada tempat tinggal, mengemis dan diabaikan oleh keluarga.

Selepas warga emas dikumpulkan di Rumah Seri Kenangan yang diasingkan daripada orang-orang papa yang lain, mereka dijaga dari segi kesihatan serta keperluannya dengan baik. Sekiranya mereka pulih dan mendapat pekerjaan, mereka akan dikeluarkan daripada rumah penjagaan tersebut. ${ }^{63}$ Selain itu, mana-mana warga emas papa akan berhubung

59 Bidin and Yusoff.the abuse of the elderly is recognized as a form of domestic violence. The legislation dealing with matters pertaining to domestic violence is Domestic Violence Act 1994 (Act 521

60 Lihat 'Pengantar' Akta 183

61 Sek 14 Akta Orang-Orang Papa 1977.

62 Akta Orang-Orang Papa (Akta 183), 1977, pp. 1-12; Noor Aza Ahmad, 'Perlindungan Kebajikan Warga Emas Gelandangan Dan Daif Menurut Akta Orang-Orang Papa 1977 : Suatu Tinjauan Perundangan.', KANUN - Jurnal Undang-Undang Malaysia, 2021, 79-96. 
dengan keluarga mereka dalam usaha merapatkan kembali hubungan mereka sehingga sekiranya ada antara ahli keluarga yang bersedia menjaga mereka, warga emas ini akan dilepaskan untuk kembali kepada penjagaan keluarga ${ }^{64}$ Langkah ini dapat mendidik ahli keluarga untuk kembali bertanggungjawab terhadap ibu bapa warga emas dan mendapat kembali hak mereka untuk dijaga oleh ahli keluarga.

Walau bagaimanapun akta ini dilihat terhad kepada penjagaan dan perlindungan bagi warga emas papa sahaja sedangkan ramai warga emas yang dianiayai oleh keluarga juga memerlukan perlindungan seperti ini. Selain itu, akta ini tidak menyatakan remedi tindakan undang-undang bagi anak-anak dan waris yang enggan menjaga ibu bapa papa ini sedangkan mereka berkemampuan. Hal ini bertentangan dengan budaya masyarakat di Malaysia dan agama Islam. Keadaan ini juga mendorong anak-anak melepaskan tanggungjawab kepada Rumah Seri Kenangan. Sungguhpun tanggungjawab ini dapat dipukul oleh Rumah Seri Kenangan dan kementerian terlibat, namun akan memberikan kesan jangka panjang yang tidak baik terhadap budaya bangsa dan ekonomi negara. Penelitian lebih lanjut dan pemerkasaan terhadap akta ini serta kaedah berkaitan, iaitu Kaedah-kaedah (Rumah Kebajikan) Orang-Orang Papa 1981 dan KaedahKaedah Pengurusan Rumah Orang Tua 1983 perlu dilakukan agar dapat diperluas bagi memenuhi keperluan warga emas yang dibuang atau didera, serta hukuman terhadap ahli keluarga yang membiarkan warga emas terbiar sedangkan mereka berkemampuan.

\section{Akta Pusat Jagaan 1993 (Akta 506)}

Akta Pusat Jagaan 1993 adalah antara undang-undang di Malaysia yang berkaitan dengan penjagaan dan perlindungan terhadap warga emas. Akta ini diwujudkan pada tahun 1993 dan berkuat kuasa pada tahun 1994. ${ }^{65}$ Akta ini bertujuan untuk mengawal selia pusat penjagaan yang berada di Malaysia termasuklah pusat penjagaan warga emas. Akta ini amat penting bagi memastikan penjagaan warga emas di pusat jagaan adalah sempurna dari aspek makanan, tempat tinggal, rawatan kesihatan dan aktiviti harian agar ibu bapa warga emas yang dihantar oleh anak-anak tetap terpelihara kebajikan mereka.

Menurut akta ini, pusat penjagaan warga emas terbahagi kepada dua jenis, iaitu pusat penjagaan kediaman yang dihuni oleh warga emas

64 Sek 8(1)(b)

65 Akta Pusat Jagaan, 1993. 
melebihi satu hari dan pusat jagaan harian, iaitu penjagaan melebihi tiga jam sehari tetapi kurang daripada dua puluh empat jam dan beroperasi sekurang-kurangnya tiga hari seminggu. Kedua-dua jenis pusat jagaan ini hendaklah membuat permohonan ${ }^{66}$ dan mendapat kelulusan daripada kementerian berkaitan sebelum layak beroperasi. Sesebuah pusat penjagaan hanya dibenarkan beroperasi setelah mematuhi aspek keselamatan Jabatan Bomba $^{67}$, keluasan lantai yang diperlukan 3.0 meter persegi bagi setiap penghuni ${ }^{68}$, mematuhi standard kesihatan dan kebersihan ${ }^{69}$ yang diperlukan, mempunyai tandas, bekalan air yang mencukupi, tempat tidur yang sesuai bagi pasangan suami isteri (bagi pusat jagaan kediaman) ${ }^{70}$, makanan yang sempurna dan bersih $^{71}$, bilik sakit atau bilik pengasingan ${ }^{72}$, peti pertolongan cemas $^{73}$ dan menyimpan rekod peribadi penghuni dengan baik. ${ }^{74}$

Kawalan pusat jagaan warga emas antara perkara penting untuk menjaga kebajikan dan memberikan perlindungan yang terbaik bagi warga emas yang tinggal di rumah jagaan ini. Namun begitu, pengkaji mendapati perlindungan terhad kepada warga emas yang menetap atau berada di rumah jagaan ini sahaja dan tidak menyeluruh bagi melindungi semua warga emas di Malaysia. Maka, sewajarnyalah agar dilaksanakan pengkajian pembangunan model yang dapat melindungi hak-hak warga emas secara lebih menyeluruh.

\section{Undang-Undang Keluarga Islam Negeri-Negeri}

Undang-Undang Keluarga Islam $^{75}$ merupakan undang-undang Islam pada peringkat negeri dan persekutuan yang mengandungi elemen perlindungan terhadap warga emas dalam konteks perkahwinan. Antara aspek yang dijelaskan dalam enakmen ini termasuklah hak perwalian ${ }^{76}$,

66 Sek 3(1).

67 Sek 11(2)

68 Sek 14(1)(b).

69 Lihat Bahagian V, Akta Pusat Jagaan 1993.

70 Sek 21(2)

71 Sek 22(1)

72 Sek $26(1)$

73 Sek 26 (3)

74 Sek 6(1)(2)

75 Enakmen Undang-Undang Keluarga Islam Negeri Selangor, 2003.

76 Sek 13 
hak pendaftaran ${ }^{77}$, hak hidup bersama ${ }^{78}$, hak pembubaran perkahwinan ${ }^{79}$, hak terhadap harta seperti mas kahwin ${ }^{80}$, nafkah ${ }^{81}$, mutaah ${ }^{82}$ dan harta sepencarian ${ }^{83}$. Aspek ini merupakan hak utama dalam perkahwinan bagi seseorang warga emas bermula dari awal perkahwinan, dalam perkahwinan seperti nafkah, ketika ditimpa kemudaratan, iaitu hak membubarkan perkahwinan dan hak selepas perkahwinan seperti harta sepencarian.

Dalam aspek sebelum perkahwinan hak untuk berkahwin telah membenarkan warga emas untuk membuat permohonan kebenaran bagi perkahwinan yang sah menurut syarak dan perundangan. Permohonan kebenaran ini dapat menolak persepsi negatif anak-anak dan keluarga yang melarang warga emas daripada berkahwin semula dan mendapatkan pasangan hidup baharu selepas berlakunya pembuburan perkahwinan atau kematian pasangan. Namun begitu, bantuan keluarga adalah perlu bagi urusan permohonan untuk membawa warga emas untuk ke pejabat agama yang berdekatan.

Aspek keperluan sara hidup enakmen ini memberikan hak warga emas untuk mendapatkan hak nafkah daripada anak-anak sekiranya tidak berupaya untuk bekerja atau ketiadaan harta. ${ }^{84}$ Seksyen 61 Enakmen Undang-Undang Keluarga Islam (EUKI) Negeri Selangor 2003, menjelaskan bahawa seseorang bertanggungjawab memberikan nafkah terhadap orang di bawah tanggungannya yang tidak berkeupayaan sepenuhnya atau sebahagiannya disebabkan isu kesihatan. Peruntukan ini memberikan ruang bagi warga emas yang tidak berkeupayaan untuk memperoleh hak nafkah mereka daripada anak-anak dan anggota keluarga. Namun begitu, peruntukan ini dilihat kurang jelas terhadap warga emas kerana penyataannya bersifat umum. Peruntukan juga tidak meliputi ibu

$77 \quad$ Sek 25

78 Sek 121

79 Sek 46- Sek 57

$80 \quad$ Sek 59

81 Sek 61

82 Sek 58

83 Sek 122

84 Siti Fatimah Salleh \& Syh Noorul Madihah Syed Husin, 'Analisis Amalan Pemberian Nafkah Warga Kelainan Upaya: Kajian Di Taman Rahmat', Journal of Business and Social Development, 2.1 (2014), 94-103; Badruddin Ibrahim and Azizah Mohd, 'Hak Ibubapa Terhadap Nafkah Dalam Perundangan Islam', Jurnal Kanun, 1 (2012), 2437; Azahari Ahmad Syakir, Mohd Nassuruddin; Raihanah, 'Pembiayaan Nafkah Ibu Bapa : Kajian Pelaksanaan Di Pasir Mas Kelantan.', in Proceedings of the International Conference on Islam, Development and Social Harmony in Southeast Asia, 2017. 
bapa yang masih sihat untuk mendapatkan hak nafkah daripada anak serta memerlukan pembuktian yang kukuh terhadap ketidakupayaan ibu bapa. Buktinya, beberapa kes tuntutan hak nafkah ibubapa yang diselesaikan di Mahkamah Syariah di Malaysia seperti dalam kes Khalil bin Ahmad lwn Kamal bin Khalil. ${ }^{85}$ Dalam kes ini Mahkamah Tinggi Syariah Negeri Sembilan memerintahkan defenden membayar kos perubatan isteri plaintif yang juga merupakan ibu defendan sebanyak RM2000.00 dalam masa tiga bulan dan RM200.00 setiap bulan kepada plaintif sebagai nafkah bulanan ekoran tidak bekerja dan uzur. Jelaslah, peruntukan ini bersifat umum dan memerlukan pentafsiran undang-undang yang merumitkan pelaksanaannya di Mahkamah.

Selain itu, enakmen ini juga memberikan pengiktirafan kepada warga emas untuk memperoleh hak penjagaan cucu dan anak-anak apabila mereka berkelayakan tanpa mengira usia mereka. ${ }^{86}$ Walaupun peruntukan ini tidak memaklumkan kategori warga emas namun istilah "nenek" yang digunakan memberikan hak kepada mereka untuk menjaga anak dan cucu mereka dengan baik. Demikian juga dalam seksyen 89 (1)(a) dan 89(1) (d) yang memberikan hak kepada warga emas lelaki, iaitu kategori datuk untuk memperoleh hak penjagaan terhadap harta orang dalam tanggungan termasuk cucu. Peruntukan ini bagi memastikan harta cucu mereka yang menjadi anak yatim atau kurang upaya dapat diuruskan dengan baik di samping menghormati warga emas sebagai asal keturunan disebelah bapa dan pengiktiran terhadap hak warga emas. Namun begitu, peruntukan ini juga bersifat umum.

Seterusnya hak selepas perkahwinan bagi warga emas yang juga dilindungi oleh enakmen ini, iaitu hak-hak terhadap harta sepencarian ${ }^{87}$, mutaah $^{88}$, nafkah idah ${ }^{89}$, nafkah tertunggak ${ }^{90}$, hak kediaman $^{91}$ dan sebagainya. Pengiktirafan hak ini memberikan ruang kepada warga emas yang telah kematian pasangan dan mengalami perceraian ketika hidup bagi meneruskan kelangsungan hidup mereka dengan pembayaran

\footnotetext{
85 (2003) 16 JH 19

86 Sek 82 (a) dan (c) Enakmen Undang-Undang Keluarga Islam Negeri Selangor, 2003.

87 Sek. 122

88 Sek 58

89 Sek 60

90 Sek 70

91 Sek 72
} 
nafkah, mutaah dan pengagihan harta sepencarian ${ }^{92}$ daripada pasangan mahupun waris. Keseluruhan hak di atas yang terkandung dalam EUKI di Negeri Selangor dan negeri-negeri lain adalah hampir sama memberikan perlindungan terhadap hak warga emas dalam perkahwinan. Walaupun tidak jelas perkataan warga emas dan definisi istilah tersebut tidak dinyatakan, namun enakmen tersebut dapat menjaga warga emas secara umum dalam perkahwinan. Walau bagaimanapun, aspek ini perlu diperluas dan diperincikan agar lebih memenuhi keperluan warga emas terutamanya dari aspek nafkah ibu bapa, hak diziarah oleh anak-anak, hak kediaman dan hukuman bagi keingkaran serta penguatkuasaan terhadap tanggungjawab tersebut. Perkara ini perlu bagi mengurangkan isu pengabaian terhadap warga emas.

\section{Undang-Undang Pentadbiran Agama Islam Negeri}

Selain EUKI, enakmen pentadbiran agama Islam negeri-negeri juga adalah antara undang-undang Islam di Malaysia yang mempunyai peruntukan berkaitan dengan perlindungan warga emas. Walaupun tidak banyak, namun sedikit sebanyak dapat memberikan perlindungan kepada warga emas seperti yang termaktub dalam Enakmen Pentadbiran Agama Islam (EPAI) Negeri Selangor 2003. Dalam EPAI, antara hak warga emas yang dinyatakan adalah yang tidak termaktub dalam EUKI, iaitu hak perwarisan, wakaf, wasiat, hibah dan nazar. ${ }^{93}$ Namun begitu, hal ini dijelaskan dalam perincian bidang kuasa Mahkamah Tinggi Syariah di bawah Seksyen 61 secara umum tanpa menjelaskan khusus peruntukan ini juga untuk warga emas.

Peruntukan secara umum ini memberikan ruang untuk warga emas serperti warga yang lain untuk membuat tuntutan yang diperlukan oleh mereka. Sudah pasti peruntukan umum ini boleh menimbulkan pelbagai

92 Norazlina Abdul Aziz, Irini Ibrahim, and Mohd Norhusairi Mat Hussin, 'Harta Sepencarian / Aset Perkahwinan Bagi Pembubaran Perkahwinan Di Bawah Undang ( Perkahwinan Dan Perceraian ) 1976 Serta Akta Undang-Undang Keluarga Islam ( Wilayah-Wilayah Persekutuan ) 1984', Journal of Shariah Law Research, 4.April 2019 (2019), 1-26; Mat Hussin Mohd Norhusairi and Abdullah Raihanah, 'Distribution Practice of Harta Sepencarian in Malaysia: A Literature Review', Journal of Shariah Law Research, 1.1 (2016), 75-88; Mohd Norhusairi Mat Hussin and others, 'Harta Sepencarian vs Harta Perkahwinan Dalam Perundangan Sivil: Satu Sorotan Ringkas', Al- Basirah, 6.1 (2016), 79-96; Akmal Hidayah Halim, 'Tuntutan Harta Sepencarian Dalam Kes Kematian', KANUN - Jurnal Undang-Undang Malaysia, 2010, $26-46$ $<$ http://irep.iium.edu.my/3446/>. 
tafsiran, kekeliruan dan ketidakfahaman dalam kalangan warga emas. Situasi ini membawa kekeliruan dan kesukaran bagi warga emas untuk membuat tuntutan tersebut yang juga menjejaskan hak mereka. Oleh itu, adalah perlu penambahbaikan terhadap enakmen ini agar lebih memenuhi keperluan warga emas dan dapat melindungi hak warga emas secara menyeluruh.

Antara perubahan yang perlu dilakukan adalah dengan memasukkan tafsiran warga emas dalam tafsiran istilah bagi memastikan perundangan yang ada meliputi ibu bapa warga emas yang sudah pasti merupakan entiti penting kepada anggota keluarga. Selain itu, adalah perlu diperincikan hak ibu bapa warga emas terhadap perwarisan, perancangan dan pengurusan harta keluarga seperti hibah, ketidakupayaan warga emas yang boleh diwakilkan kepada penjaga secara jelas, tanggungjawab anak-anak dan penjaga untuk melaksanakan nazar dan wasiat ibu bapa warga emas, tanggungjawab pengurusan hutang ibu bapa warga emas, badal haji dan sebagainya. Sudah tiba masanya peruntukan yang jelas berkaitan dengan ibu bapa warga emas diperincikan dalam enakmen ini bagi kesediaan menghadapi Malaysia sebagai "negara tua" pada tahun 2035 tanpa melampaui bidang kuasa negeri.

\section{KESIMPULAN}

Perundangan sedia ada di Malaysia didapati telah menyediakan perlindungan terhadap hak warga emas dan memenuhi sebahagian daripada prinsip yang dianjurkan oleh United Nation Principle For Older Persons (UNPOP) 1991. Namun begitu, perlindungan tersebut adalah secara umum serta masih kurang memenuhi aspek perlindungan yang menyeluruh yang diperlukan oleh warga emas seperti dasar dan polisi yang digariskan di dalamnya. Terdapat aspek yang belum disentuh sama ada secara umum mahupun secara khusus seperti perlindungan agama, maruah dan keturunan warga emas sebagai manusia yang perlu dihormati seperti yang dikehendaki oleh Islam. Peruntukan yang ada juga kurang memenuhi keperluan warga emas ekoran penggubalan undang-undang tersebut adalah untuk tujuan lain seperti untuk perlindungan wanita dan keluarga tanpa memfokuskan terhadap warga emas khususnya yang tidak berkeluarga. Oleh yang demikian, adalah suatu keperluan untuk mendepani peningkatan populasi warga emas negara, untuk dilakukan pindaan terhadap perundangan sedia ada, mahupun menggubal undangundang yang khusus agar pelaksanaan perlindungan terhadap golongan rentan ini dapat dilakukan secara lebih menyeluruh. 


\section{RUJUKAN}

Ahmad, Muhammad Hazim, et al. (2019). Undang-Undang penjagaan dan kebajikan warga emas di Malaysia: Satu Analisis Awal. E-Prosiding Persidangan Industri Warga Emas Kebangsaan 2019: Menuju Pengurusan Patuh Syariah. Usuli Faqih Research Centre Plt.

Ahmad, Noor Aza. (2021). Perlindungan kebajikan warga emas gelandangan dan daif menurut Akta Orang-Orang Papa 1977: Suatu tinjauan perundangan. Kanun: Jurnal Undang-Undang Malaysia, 33(1), 79-96.

Ahmad Syakir, et al. (2017). Pembiayaan Nafkah Ibu Bapa : Kajian Pelaksanaan Di Pasir Mas Kelantan. Mohd Nasran Mohamad, et al. (Ed.), Proceedings of the International Conference on Islam, Development and Social Harmony in Southeast Asia 2017. Fakulti Pengajian Islam, UKM.

Akta Keganasan Rumahtangga 1994 [Akta 521].

Akta Orang-Orang Papa 1977 [Akta 183].

Akta Pusat Jagaan 1993 [Akta 506].

Badruddin Ibrahim \& Azizah Mohd. (2012). Hak ibubapa terhadap nafkah dalam perundangan Islam. Kanun: Jurnal Undang-undang Malaysia, 24(1), 24-37.

Bidin, Asiah, et al. (2015). Abuse of the Malaysian elderly: An analysis on the adequacy and suitability of the Domestic Violence Act 1994 (Act 521) to protect the elderly victim. Journal of Management Research, 7 (2), 71-81. doi.org/10.5296/jmr.v7i2.6928

Enakmen Undang-Undang Keluarga Islam Negeri Selangor 2003.

Gordon, et al. (2001). The abuse and neglect of the elderly. International Journal of Law and Psychiatry, 24, 183-197.

Halim \& Akmal Hidayah. (2010). Tuntutan Harta Sepencarian Dalam Kes Kematian. Kanun: Jurnal Undang-Undang Malaysia, 22(1), 26-46.

Hamid, et al. (2008). National policy for the elderly in Malaysia: Achievements and challenges. Hock Guan Lee (Ed.), Ageing in Southeast and East Asia: Family, Social Protection, Policy Challenges. ISEAS Publishing. http//:doi. org/10.1355/9789812307941-009

Jabatan Kebajikan Masyarakat Malaysia, (2015). Dasar Warga Emas Negara. http//:doi.org/10.1017/CBO9781107415324.004

Kementerian Pembangunan Wanita Keluarga dan Masyarakat. (2015). Pelan Tindakan Warga Emas Negara (PTWEN). http://www.kpwkm.gov.my/ dasar1?p_p_id=XY_CMS_MULTI_WAR_xycmsp?_XY_CMS_MULTI_ WAR_xycmsportlet_INSTANCE_FC8h_andOperator=true

Kementerian Pembangunan Wanita, Keluarga Dan Masyarakat, (2016). Dasar Kesihatan Warga Emas Negara, 1-21. http//:doi.org/10.1017/ CBO9781107415324.004

Laporan Berita Harian Online. (2019). Tak Mengaku Salah Mengugut Ibu Sendiri. https://www.bharian.com.my/berita/kes/2019/03/538422/tak-mengaku-salahmengugut-ibu-sendiri. Diakses pada 7 September 2021. 
Laporan Harian Metro. (2017). Kian ramai warga tua didera. https://www.hmetro. com.my/sihat/2017/07/243481/kian-ramai-warga-tua-didera. Diakses pada 17 Mac 2018.

Lim, Che Kiong, (2012). The changing needs of older Malaysians: A Selangor case study. Discipline of Geography, Environment and Population Faculty of Humanities and Social Sciences. The University of Adelaide, Adelaide.

Loke, Seng Cheong, et al. (2011). Assessment of factors influencing morale in the elderly. PLoS ONE, 6 (1), 1-8. doi.org/10.1371/journal.pone.0016490

Mohd Norhusairi Mat Hussin \& Abdullah Raihanah, (2016). Distribution practice of harta sepencarian in Malaysia: A literature review. Journal of Shariah Law Research, 1(1), 75-88.

Nor Raudah Siren, (2015). Psikologi dan penerimaan warga emas di kompleks warga emas Al-Jenderami. Jurnal Usuluddin, 41, 73-93.

Norazlina Abdul Aziz, et al. (2019). Harta sepencarian / aset perkahwinan bagi pembubaran perkahwinan di bawah undang (perkahwinan dan perceraian) 1976 serta Akta Undang-Undang Keluarga Islam (Wilayah-Wilayah Persekutuan) 1984. Journal of Shariah Law Research, 4(1), 1-26.

Norhusairi Mat Hussin \& Mohd Hafiz Jamaludin, (2016). Harta sepencarian vs harta perkahwinan dalam perundangan sivil: Satu sorotan ringkas. Al-Basirah, 6(1), 79-96.

OHCHR (2021). United Nations Principles for Older Persons. https://www.ohchr. org/en/professionalinterest/pages/olderpersons.aspx. Diakses pada 22 Ogos 2021.

Overbury, Olga, et al. (2005). United Nations' principles for older persons viewed though the eyes of visually impaired seniors. International Congress Series, $428-432$.

Perlembagaan Persekutuan Malaysia 1963.

Portal Rasmi Jabatan Kebajikan Masyarakat (2020). http://www.jkm.gov.my/ jkm/index.php?r=portal/left\&id=VzNXN1VHM0hxZ3VqWWhZSORhMDZ idz09. Diakses pada 24 Mac 2020.

Sarin Johari, et al. (2018). Perbandingan tahap kualiti hidup bagi warga emas yang mendapatkan perkhidmatan di pusat aktiviti warga emas (PAWE) di kawasan bandar dan luar bandar. Jurnal Psikologi Malaysia, 32(3), 82-90.

Siti Fatimah Salleh \& Syh Noorul Madihah Syed Husin, (2014). Analisis Amalan pemberian nafkah warga kelainan upaya: Kajian di Taman Rahmat. Journal of Business and Social Development, 2(1), 94-103.

Tengku Aizan Hamid, (2018). National policies on ageing- Malaysia, ageing and long-term care, doi.org/10.1355/9789812307163-007

Yusoff, Jal Zabdi Mohd, (2009). Jenayah dalam keluarga: Penderaan dan pengabaian warga tua di Malaysia. International Conference on Corporate Law (ICCL). 